\title{
Sociodemographic and lifestyle correlates of exclusive breastfeeding practices among mothers on antiretroviral therapy in the Eastern Cape, South Africa
}

Daniel Ter Goon ${ }^{1}$, Anthony Idowu Ajayi ${ }^{2,3}$ and Oladele Vincent Adeniyi ${ }^{1,4^{*}}$ (D)

\begin{abstract}
Background: Exclusive breastfeeding (EBF) is associated with a reduction of postnatal HIV transmission and optimal infant growth. Given that the factors influencing exclusive breastfeeding are multi-factorial and context-specific, we examined the prevalence and factors associated with exclusive breastfeeding practice in the first 6 months among mothers on antiretroviral therapy in the Eastern Cape, South Africa.
\end{abstract}

Methods: This was a cross-sectional study conducted between January to May 2018, on 469 parturient women enlisted in the prevention of mother-to-child HIV transmission cohort study in the Eastern Cape. Mothers were asked to recall whether they breastfed their infant exclusively with breast milk from birth and if so, to state how long they did. We collected relevant sociodemographic, lifestyle, and maternal information by interview. Bivariate and multivariable logistic regression analyses were fitted to determine the sociodemographic and lifestyle factors associated with exclusive breastfeeding practice.

Results: The prevalence of six-month exclusive breastfeeding, measured since birth, was 32.0\%. E Exclusive breastfeeding's prevalence was significantly higher among married women (36.8\%), unemployed women (36.6\%), non-smokers (32.7\%), and those who never drank alcohol (37.0\%). Unemployed women (adjusted odds ratio [AOR] 1.66, 95\% Confidence Interval [CI] 1.08-2.56) and those with grade 12 or less level of education (AOR 2.76, 95\% Cl 1.02-7.49) had a higher likelihood of practising EBF for 6 months since birth while mothers who consumed alcohol (AOR $0.54,95 \% \mathrm{Cl} 0.34-0.85$ ) were less likely to practice EBF for 6 months.

Conclusions: The prevalence of six-month exclusive breastfeeding in the study, although comparable with subSaharan Africa and worldwide prevalence, remains suboptimal. Advocacy campaigns on EBF must target alcohol cessation and the creation of a favourable workplace environment for lactating mothers.

Keywords: Infants, Exclusive breastfeeding, HIV, Antiretroviral therapy, South Africa

\footnotetext{
* Correspondence: vincoladele@gmail.com

${ }^{1}$ Department of Public Health, University of Fort Hare, 5 Oxford Street, East London 5201, South Africa

${ }^{4}$ Department of Family Medicine, East London Hospital Complex, Cecilia

Makiwane Hospital, East London, South Africa

Full list of author information is available at the end of the article
}

(c) The Author(s). 2021 Open Access This article is licensed under a Creative Commons Attribution 4.0 International License, which permits use, sharing, adaptation, distribution and reproduction in any medium or format, as long as you give appropriate credit to the original author(s) and the source, provide a link to the Creative Commons licence, and indicate if changes were made. The images or other third party material in this article are included in the article's Creative Commons licence, unless indicated otherwise in a credit line to the material. If material is not included in the article's Creative Commons licence and your intended use is not permitted by statutory regulation or exceeds the permitted use, you will need to obtain permission directly from the copyright holder. To view a copy of this licence, visit http://creativecommons.org/licenses/by/4.0/. The Creative Commons Public Domain Dedication waiver (http://creativecommons.org/publicdomain/zero/1.0/) applies to the data made available in this article, unless otherwise stated in a credit line to the data. 


\section{Background}

Exclusive breastfeeding (EBF) could save the lives of infants and prevent mother-to-child transmission (PMTCT) of HIV infection [1, 2], especially in a country like South Africa with a high HIV burden [3, 4]. Between 2010 and 2015, South Africa has made policy changes in infant feeding practices and PMTCT guidelines. The policy changes resulted in the replacement of free infant formula for EBF for 6 months policy. Mothers are counselled to practice EBF in the first 6 months, continue to breastfeed beyond 6 months whilst introducing complementary feeding. Also, the new policy recommended the adoption of WHO Option $\mathrm{B}+$ (lifelong antiretroviral therapy strategy) for all HIV-infected pregnant and postpartum women, irrespective of their immune suppression status or infant feeding choice $[1,5,6]$.

Established global evidence has shown that exclusive breastfeeding prevents both the incidence of and mortality from diarrhoea, which is commonly associated with mixed feeding practices and infant formula feeding practices [7]. Overall, EBF confers the benefits of essential nutrients and robust immune systems, reduction in the risk of malnutrition and diarrheal associated-illnesses, which are the leading causes of infant mortality in developing nations [1, 8-10]. Worryingly, even with available data demonstrating unequivocal benefits of EBF, mothers often do not abide by the recommended 6 months of EBF [11-13], thus, putting infants at high risk of death. The low EBF prevalence is underpinned by several factors, thus suggesting that there is more to learn and understand regarding the prevailing reasons for the reluctance of mothers to breastfeed their infants exclusively. Previous studies conducted in South Africa have indicated contradictory infant feeding messages from older relatives, such as grandmothers, and healthcare workers, low socio-economic indicators, and the fear of transmitting HIV to the infant as among the reasons for mixed-feeding practices [10, 14].

Exclusive breastfeeding prevalences are reportedly low in many countries, despite the manifold benefits accruable from breastfeeding [15-17]. As reported by Victoria et al. [16] study, only $37 \%$ of children are exclusively breastfed in developing countries. In sub-Saharan Africa, the prevalence of EBF is $36 \%$ [17], which is very low compared with the global EBF target prevalence set at $50 \%$ by 2025 [18]. In South Africa, the government effort has yielded some modest improvement in the prevalence of EBF among mothers living with HIV over the years [19]. However, with an estimation of $31.6 \%$ EBF prevalence, the country remains below global targets $[15,20$, 21]. The fear of HIV transmission and status disclosure is among the reasons for the low prevalence of exclusive breastfeeding [22, 23].
Considering the high HIV epidemic in South Africa, with approximately 7.7 million people with HIV [24], understanding the factors associated with EBF is essential in crafting strategies to support and sustain appropriate breastfeeding practices to increase the prevalence of exclusive breastfeeding. Even though previous studies have examined the prevalence of EBF among lactating mothers living with HIV in South Africa [10, 15, 17, 20, 25-28], scanty information exists in the Eastern Cape, a province with a twin burden of HIV epidemic and poverty. Given that factors affecting EBF practices vary among countries and even within the sub-groups of populations [29], contextual information on the prevalence and determinants of EBF is vital to inform contextspecific interventions. Hence, this study seeks to examine the prevalence and the factors influencing EBF practices among mothers receiving antiretroviral therapy (ART) in the Eastern Cape Province, South Africa.

\section{Methods \\ Study design, settings, population, and sample}

This cross-sectional study was conducted between January to May 2018 and forms part of a larger project to assess maternal and infant outcomes for the prevention of mother-to-child transmission programme in the Eastern Cape, South Africa. Aspects of the methodology have been previously published elsewhere [30, 31]. Briefly, the target population was parturient women on ART and their infants attending maternity health facilities at Frere, Cecilia Makiwane, and Bisho hospitals. The baseline study was carried out between September 2015 and May 2016 in the Eastern Cape, South Africa. At the time of the data collection, the infant ages range from 18 to 29 months.

All the parturient women on ART $(n=1709)$ gave consent to be contacted for the follow-up study and also provided three phone contacts through which they could be reached. We were successful in reaching 509 contacts. Nine women had died, and six declined to participate in the study, while 26 dropped out of the survey without answering questions on exclusive breastfeeding. Overall, we included 469 participants in this study. The sample of 469 participants is enough to achieve $88 \%$ statistical power to detect a difference of $15 \%$ in exclusive breastfeeding practice of users and non-users of alcohol, at an alpha value of 0.005 assuming an EBF prevalence of $36 \%$ (17).

The Research Ethics Committee of the Walter Sisulu University approved the research protocol. The nature and scope of the study were explained to the participants, whom all gave informed consent before data collection.

\section{Data collection procedure}

Participants were contacted telephonically to participate in this study, using the three phone contacts provided 
during the baseline survey. Each participant was provided with an option to either visit the nearest hospital for a face-to-face interview or be interviewed via telephone. Two research assistants were trained to complete the interviewer-guided interview using a pre-designed and validated questionnaire. They were trained mainly on the data collection instruments and the sensitivity of the topic under study.

Participants for telephonic interviews were asked to provide a convenient time for the interview. Research assistants could fluently speak and write English and the local language of IsiXhosa. A structured questionnaire was designed to obtain information on sociodemographic variables (age, employment, marital status, and level of education), postpartum adherence to ART, and behavioural lifestyles (smoking and alcohol intake).

\section{Outcome variable}

The primary outcome of interest was EBF practice in the first 6 months. Exclusive breastfeeding is defined by WHO as "nothing but breast milk" [2]. This was measured by asking mothers if they initiated EBF for their baby and, if yes, to state the duration of EBF in months. Mothers who breastfed their infants exclusively for 1 to 3 weeks were coded as 1 month.

\section{Independent variables}

The independent variables included in this study were sociodemographic factors, such as age, employment, marital status, level of education, postpartum adherence to ART, and behavioural lifestyle factors such as smoking and alcohol intake. Our variable selection was based on our review of the literature. Age was measured by asking respondents to state their age at their last birthday. Employment was measured by asking if respondents had worked for wages or salary in the past 12 months or not. Also, we asked participants to indicate if they were single, married, cohabiting or divorced. We also asked respondents to indicate the highest level of education they attained.

We defined postpartum adherence to ART as any episode of missed doses of ART since the birth of the index baby. Mothers who had missed taking their ART were classified as non-adherent, and those who reported no missed episode of ART were classified as adherent. Also, we asked respondents to indicate if they had ever used alcohol and if they smoke tobacco products. Responses were classified as "yes" or "no".

\section{Statistical analysis}

All statistical analyses were carried out using the Statistical Package for Social Sciences (SPSS) for Windows version 24.0 (SPSS, Chicago, IL, USA). We estimated mean, standard deviation, and proportions for all continuous and categorical variables. Inferential statistics (crude and adjusted logistic regression models) were used to examine factors influencing EBF practices among mothers on antiretroviral therapy. We first estimated the unadjusted odds ratio for all sociodemographic, behavioural, and clinical factors. After, we computed an adjusted odds ratio to identify the main factors significantly associated with the practice of exclusive breastfeeding.

\section{Results}

The participants' mean age was $33 \pm 5.7$ years. The majority of the participants were 30 years and above (69.3\%), single (66.3\%), had grade 12 level of education (87.4\%), unemployed (61.8\%), and were on government social grant $(94.5 \%)$. Only a few participants smoked (8.1\%) or drank alcohol (35.4\%) (Table 1).

\section{Prevalence of exclusive breastfeeding}

The prevalence of six-month EBF was $32.0 \%$. The prevalence of EBF was significantly higher among married women $(36.8 \% ; p<0.001)$, unemployed women $(36.6 \%$; $p<0.026)$, non-smokers $(32.7 \%)$, and those who never drank alcohol $(37.0 \% ; p<0.001)$ (Table 2).

Factors associated with six-month exclusive breastfeeding practices (multivariate logistic regression analysis)

We selected variables into our model based on our review of the literature of factors shown to influence exclusive breastfeeding. Variables reported to be significant in previous studies were included in our model irrespective of their $p$ - values in our bivariate analysis. For example, we adjusted for age even though it did not reach a significant level in our bivariate analysis. We did not include "receiving of social grant" and "engaged in a salary paying job" due to their collinearity with "occupation". The results of the unadjusted logistic regression analysis indicate that being unemployed (Crude Odds Ratio [COR] 1.77, 95\% CI 1.17, 2.68) and having attained grade 12 or less education (COR 2.79, 95\% CI 1.06, 7.38) were significantly associated with a higher odds of practising EBF for the first 6 months by the participants (Table 3).

However, alcohol use was associated with lower odds of practising EBF among the study participants (COR 0.51, 95\% CI 0.33, 0.78). The clinical parameters: duration of disease, disclosure of serostatus, and adherence to the current ART had no significant association with EBF practice among the mothers. Similarly, in the adjusted model, being unemployed (AOR 1.66, 95\% CI $1.08,2.56 ; p<0.05)$ and having grade 12 or less level of education (AOR 2.76, 95\% CI, 1.02, 7.49; $p<0.05$ ) were significantly associated with a higher likelihood of exclusive breastfeeding, while alcohol use was significantly 
Table 1 Sociodemographic characteristics of participants

\begin{tabular}{|c|c|c|}
\hline Variables & Frequency & Percentage \\
\hline \multicolumn{3}{|l|}{ Age } \\
\hline 24 years and less & 33 & 7.0 \\
\hline 25-29years & 111 & 23.7 \\
\hline 30-34 years & 137 & 29.2 \\
\hline $35-39$ years & 121 & 25.8 \\
\hline 40 years and above & 67 & 14.3 \\
\hline \multicolumn{3}{|l|}{ Marital status } \\
\hline Single & 311 & 66.3 \\
\hline Married & 125 & 26.7 \\
\hline Cohabiting & 25 & 5.3 \\
\hline Previously married & 8 & 1.7 \\
\hline \multicolumn{3}{|l|}{ Education level } \\
\hline Grade 7 and less & 27 & 5.8 \\
\hline Grade 8-12 & 410 & 87.4 \\
\hline Higher education & 32 & 6.8 \\
\hline \multicolumn{3}{|l|}{ Employed in a salary paying job } \\
\hline Yes & 151 & 32.2 \\
\hline No & 318 & 67.8 \\
\hline \multicolumn{3}{|l|}{ Occupation in last 12 months } \\
\hline Government employee & 15 & 3.2 \\
\hline Non-government employee & 112 & 23.9 \\
\hline Self employed & 29 & 6.2 \\
\hline Student & 23 & 4.9 \\
\hline Unemployed & 290 & 61.8 \\
\hline \multicolumn{3}{|l|}{ Receives government social grant } \\
\hline Yes & 443 & 94.5 \\
\hline No & 26 & 5.5 \\
\hline \multicolumn{3}{|l|}{ Smoking } \\
\hline Yes & 38 & 8.1 \\
\hline No & 431 & 91.9 \\
\hline \multicolumn{3}{|l|}{ Drank alcohol in the last year } \\
\hline Yes & 166 & 35.4 \\
\hline No & 303 & 64.6 \\
\hline \multicolumn{3}{|c|}{ Age of index babies at the time of the interview } \\
\hline 18-24 months & 118 & 25.2 \\
\hline $25-29$ months & 281 & 74.8 \\
\hline
\end{tabular}

associated with lower odds of six-month exclusive breastfeeding (AOR 0.54, 95\% CI 0.34, 0.85; $p<0.05$ ). The magnitude and the direction of effect persist after adjusting for important demographic, clinical, and behavioural covariates (Table 3).

\section{Discussion}

Our study aimed to examine the prevalence and factors influencing six-month EBF practice among mothers on
ART in the Eastern Cape Province, South Africa. Although programmes on 6 months of infant breastfeeding have been developed and approved in South Africa, the uptake of EBF remains low. In this study, the prevalence of six-month EBF of $32.0 \%$ was sub-optimal. However, direct comparison of EBF prevalence in this study with many other studies on EBF practice is a difficult task, given the variations in the definitions of EBF in different studies, the timing, duration of recall, methods of analysis, and sample biases [32]. Notwithstanding, the EBF prevalence obtained in this study is comparable to $31.6 \%$ among infants exclusively breastfeed for the first 6 months after delivery in Malawi, which was measured by recall method [33].

Generally, the low prevalence of EBF in South Africa is worrying and suggests concerted interventions to promote, support, and protect breastfeeding, beyond policy and programme formulations are needed. Some studies in other provinces in South Africa reported higher EBF prevalence at $43.2 \%$ among HIV-positive mothers in Merafong sub-district in Gauteng [34], and 35.6\% in Gert Sibande district in Mpumulanga [35]. An earlier study by Siziba et al. [25] reported a low summative prevalence of $12.0 \%$ in North-West, Gauteng, Free State, and Eastern Cape Provinces. Also, 18.0, 6.0, 13.0, 7.6, and $6.7 \%$ of mothers practiced EBF up to 6 months in Kwa-Zulu Natal, Western Cape, Limpopo and Gauteng provinces, respectively [36-40]. Compared with other settings elsewhere, the EBF prevalence in our study is almost at par with prevalences reported in Ethiopia (30.6, $31.0 \%$ ) [41, 42], Bangladesh (35.0\%) [43] and India (34.0\%) [44], but higher than the EBF prevalence reported in Kaiyuan Yunnan, Southwest China (27.34\%) [45], Saudi Arabia (24.4\%) [46], USA (16.8\%) [47], Egypt (9.7\%) [48] and Nigeria (14.8\%) [49]. Yet, other studies have reported higher EBF prevalence in Ethiopia (88.8, $75.2 \%$; 77.3\%) [28, 50, 51], Kenya (71.4\%; 52.3\%) [52, 53], Western India (61.5\%) [54] and Tanzania (55.5\%) [55]. The differences in EBF prevalences reported across various countries or regions in the literature could be explained in the light of differences in the definition of EBF and geographic variations in the interplay of cultural, economic, and sociodemographic factors affecting exclusive breastfeeding.

Notwithstanding the many advantages of breastfeeding and the strategies to promote it, EBF uptake still remains low in many developing countries [16, 56]. Worryingly, worldwide, only $35 \%$ of infants are exclusively breastfed [57]. Exclusive breastfeeding is associated with a reduction in child mortality in low-income countries $[58,59]$; thus, interventions on EBF should be accorded top priority. In this regard, there is a need to sensitise the community on the benefits and inherent problems associated with mixed feeding [47]. In the South African context, 
Table 2 Correlates of six-month exclusive breastfeeding

\begin{tabular}{|c|c|c|c|}
\hline Variables & $\begin{array}{l}\text { Breastfed exclusively for } 6 \text { months } \\
n(\%)\end{array}$ & $\begin{array}{l}\text { Did not breastfeed exclusively for } 6 \text { months } \\
n(\%)\end{array}$ & $P$ - value \\
\hline \multicolumn{4}{|l|}{ Age } \\
\hline 24 years and less & $11(33.3)$ & $22(66.7)$ & \multirow[t]{5}{*}{0.864} \\
\hline $25-29$ years & $38(34.2)$ & $73(65.8)$ & \\
\hline 30-34 years & $41(29.9)$ & $96(70.1)$ & \\
\hline $35-39$ years & $36(29.8)$ & $85(70.2)$ & \\
\hline 40 years and above & $24(35.8)$ & $43(64.2)$ & \\
\hline \multicolumn{4}{|l|}{ Marital status } \\
\hline Single & $92(29.6)$ & $219(70.4)$ & \multirow[t]{4}{*}{0.001} \\
\hline Married & $46(36.8)$ & $79(63.2)$ & \\
\hline Cohabiting & $9(36.8)$ & $16(64.0)$ & \\
\hline Previously married & $3(37.5)$ & $5(37.5)$ & \\
\hline \multicolumn{4}{|l|}{${ }^{2}$ Education level } \\
\hline Grade 7 and less & $9(33.3)$ & $18(66.7)$ & \multirow[t]{3}{*}{0.170} \\
\hline Grade $8-12$ & $136(33.3)$ & $237(66.7)$ & \\
\hline Higher education & $5(16.7)$ & $25(83.3)$ & \\
\hline \multicolumn{4}{|l|}{ Employed in a salary paying job } \\
\hline Yes & $45(29.8)$ & $106(70.2)$ & \multirow[t]{2}{*}{0.278} \\
\hline No & $105(33.0)$ & $213(67.0)$ & \\
\hline \multicolumn{4}{|l|}{ Occupation in the last 12 months } \\
\hline Government employee & $2(13.3)$ & $13(86.7)$ & \multirow[t]{5}{*}{0.026} \\
\hline Non-government employee & $33(29.5)$ & 79 (70.5) & \\
\hline Self employed & $4(13.8)$ & $25(86.2)$ & \\
\hline Student & $5(21.7)$ & $18(78.3)$ & \\
\hline Unemployed & $106(36.6)$ & $184(63.4)$ & \\
\hline \multicolumn{4}{|l|}{ Smoking } \\
\hline Yes & $9(23.7)$ & $29(76.3)$ & \multirow[t]{2}{*}{0.168} \\
\hline No & $141(32.7)$ & $290(67.3)$ & \\
\hline \multicolumn{4}{|l|}{ Drank alcohol in the last year } \\
\hline Yes & $38(22.9)$ & $128(77.1)$ & \multirow[t]{2}{*}{0.001} \\
\hline No & $112(37.0)$ & $191(63.0)$ & \\
\hline
\end{tabular}

${ }^{\mathrm{a} S o m e ~ p a r t i c i p a n t s ~ d i d ~ n o t ~ p r o v i d e ~ r e s p o n s e s ~ o n ~ f e e d i n g ~ p r a c t i c e s ~}(n=39)$

one of the pragmatic approach to promote women's awareness of EBF, outside of health facility channels, could be to utilise and encourage the Ward-BasedOutreach-Teams (WBOT) in the community or women's groups to increase the duration of EBF. One of the cardinal objectives of WBOT is to promote and create awareness on various health issues affecting the community as part of the government efforts of improving the primary healthcare re-engineering agenda. This is advisable because community beliefs could have considerable influence on EBF practice.

Our findings demonstrated that being unemployed and having a low level of education (secondary or less) was significantly associated with a higher likelihood of exclusive breastfeeding. In contrast, alcohol use was significantly associated with lower odds of six-month exclusive breastfeeding practice. Previous studies have linked maternal employment with lower prevalences of EBF and earlier cessation of breastfeeding $[60,61]$. In this study, consistent with studies conducted in Bangladesh [43], Saudi Arabia [46], Ethiopia [62-64], Tanzania [65], Canada [66], and Guatemala [67], unemployed mothers are likely to practise EBF as compared to those who are employed. It is plausible that mothers who are not employed do have enough opportunity while at home to breastfeed their infants. Contrastingly, employed mothers, perhaps due to the nature of their work with the challenge to return early to work after giving birth, 
Table 3 Crude and adjusted binary logistic regression analysis showing factors associated with 6 months of exclusive breastfeeding

\begin{tabular}{|c|c|c|}
\hline Variables & COR $(95 \% \mathrm{Cl})$ & AOR $(95 \% \mathrm{Cl})$ \\
\hline \multicolumn{3}{|l|}{ Age } \\
\hline 24 years and less & $0.90(0.37,2.16)$ & $1.12(0.43,2.92)$ \\
\hline $25-29$ years & $0.93(0.49,1.76)$ & $1.02(0.51,2.01)$ \\
\hline 30-34 years & $0.77(0.41,1.42)$ & $0.73(0.39,1.40)$ \\
\hline $35-39$ years & $0.76(0.40,1.43)$ & $0.68(0.36,1.32)$ \\
\hline 40 years and above & 1 & 1 \\
\hline \multicolumn{3}{|l|}{ Marital status } \\
\hline Single & $0.72(0.48,1.09)$ & $0.74(0.48,1.14)$ \\
\hline Married, cohabiting/divorce & 1 & 1 \\
\hline \multicolumn{3}{|l|}{ Education level } \\
\hline Grade 12 and less & $2.79(1.06,7.38)^{*}$ & $2.76(1.02,7.49)^{*}$ \\
\hline Higher education & 1 & 1 \\
\hline \multicolumn{3}{|c|}{ Occupation in the past 12 months } \\
\hline Unemployed & $1.77(1.17,2.68)^{*}$ & $1.66(1.08,2.56)^{*}$ \\
\hline Employed & 1 & 1 \\
\hline \multicolumn{3}{|l|}{ Smoking } \\
\hline Yes & $0.64(0.29,1.39)$ & $0.89(0.39,2.03)$ \\
\hline No & 1 & 1 \\
\hline \multicolumn{3}{|l|}{ Drank alcohol in the past year } \\
\hline Yes & $0.51(0.33,0.78)^{*}$ & $0.54(0.34,0.85)^{*}$ \\
\hline No & 1 & 1 \\
\hline \multicolumn{3}{|l|}{ Adherence to ART } \\
\hline No & $0.75(0.49,1.13)$ & $0.80(0.52,1.25)$ \\
\hline Yes & 1 & \\
\hline \multicolumn{3}{|l|}{ Disclosure of status to partner } \\
\hline No & $0.68(0.39,1.16)$ & $0.80(0.45,1.40)$ \\
\hline Yes & 1 & \\
\hline \multicolumn{3}{|l|}{ Duration of disease (Years) } \\
\hline 5 years and less & $1.02(0.69,1.50)$ & $1.03(0.66,1.62)$ \\
\hline Above 5 & 1 & 1 \\
\hline
\end{tabular}

work shifts, and maternal fatigue, may collectively hinder them from having frequent contact with their infant to provide exclusive breastfeeding. In South Africa, working mothers are granted only 4 months of maternity leave, which may begin at any time from at least 4 weeks before the birth of the baby, and there are no available workplace facilities for mothers to breastfeed children. The Code of Good Practice on the protection of employees during pregnancy and after childbirth included in the Basic Conditions of Employment Act (Republic of South Africa, 1997), stipulated that arrangement should be made to accommodate employees who are breastfeeding, with $30 \mathrm{~min}$ breastfeeding breaks twice a day to breastfeed or express for the first 6 months of the child's life (paragraph 5.13) (the Republic of South Africa, Department of Labour, 1998). However, the actual situation is that women employees and their employers are mostly unaware of this legislation on breastfeeding breaks $[68,69]$, which are seldom provided or requested in the workplace. Policies about maternity leave in South Africa warrant scrutiny to encourage EBF practice. This is very crucial in the context of achieving comprehensive PMTCT.

In this study, mothers with a low level of education are inclined to practise exclusive breastfeeding. Previous studies have reported similar findings [43, 70-73]. However, Mango et al. [16] study in Tanzania found the level of education had no association with EBF practice. Other studies conducted in Ethiopia and Bangladesh reported similar findings $[74,75]$. The association of a lower level of education with EBF could be explained by the higher rate of unemployment in this population. As such, strategies aimed at strengthening EBF practise in this population should also address the needs of women with higher levels of education. Specifically, the concerns and fears of educated women need to be addressed during counselling sessions at antenatal and postnatal clinics.

This study revealed that alcohol use was significantly associated with lower odds of six-month exclusive breastfeeding practice. About $22.9 \%$ of mothers drink alcohol. A survey conducted in the Kilimanjaro region, Tanzania, showed that mothers' alcohol intake was associated with EBF up to 6 months [73]. Other studies have reported similar findings elsewhere [70-72, 76]. However, Mgongo et al. [56] reported a contrary result. Previous studies have linked alcohol intake with HIV and poor child immunisation [77, 78]. A recent study has reported high binge drinking (10.8\%) among women in South Africa [79]. Alcohol consumption is widely practised in South Africa [79], at various events or celebrations such as weddings, burials, and other social events, work or community engagements. Advocacy programmes on the effects of alcohol intake during lactating are crucial. Alcohol use, whilst breastfeeding, has negative effects on newborns, EBF, and general infant growth [80, 81].

\section{Limitations}

Though the measure of EBF (nothing but breast milk) and its duration was clearly explained to the mothers, we could not ascertain if there was any confusion between maternal definitions of EBF and the EBF definition in this study. Often, retrospective data collection tends to result in overestimation of the prevalence and duration of EBF practice in general [32]. Hence, the extent of recall bias and social desirability bias cannot be 
ascertained, given that this study was a follow up of an existing cohort, which occurred between 18 to 29 months after the delivery of the index infants. Also, telephonic survey with its inherent challenges might have impacted the responses of the parturient women. Regardless of these limitations, our study provides useful information for future comparative studies on the factors influencing infant-feeding practices by mothers on antiretroviral therapy in the Eastern Cape Province, South Africa. Such information would be relevant in shaping maternal and child health interventions in the context of paediatric HIV infection, at least in this setting. A qualitative study would provide better insight and understanding of the reasons why the majority of the women did not practise EBF in the region.

\section{Conclusions}

The prevalence of exclusive breastfeeding in the study, although comparable with sub-Saharan Africa and worldwide prevalence, remains suboptimal. Interventions aimed at promoting, supporting, and protecting breastfeeding beyond policy and programme formulations are urgently needed in the region. The factors affecting the EBF of HIV-positive mothers in this study include employment, low levels of education, and alcohol consumption. A general advocacy campaign on exclusive breastfeeding must target alcohol cessation and the creation of a favourable workplace environment for lactating mothers.

\section{Abbreviations}

AOR: Adjusted Odds Ratio; ART: Anti-Retroviral Therapy; COR: Crude Odds Ratio; Cl: Confidence Interval; EBF: Exclusive Breastfeeding; PMTCT: Prevention of Mother-to-Child Transmission; WBOT: Ward-Based-Outreach-Teams; WHO: World Health Organization

\section{Acknowledgements}

We thank the management of Bisho, Cecilia Makiwane, and Frere hospitals. We appreciate Ms. Tembisa Sizani, Mrs. Talita Plaatjie, Mrs. Nkosazana Jwacu, Ms. Rosemond Billie and the Relevance Network team for their contributions toward the successful completion of this project.

\section{Authors' contributions}

All authors were actively involved in the conception, design, and implementation of the study protocol. DTG, OVA, and AIA drafted the manuscript while AIA performed the statistical analysis. All authors have read and approved the final draft for submission.

\section{Funding}

The South African AIDS Vaccine Initiative supported this work under the auspices of the South African Medical Research Council [Grant Number: SAMRC/03/2017] with funds received from the South African National Department of Health and awarded to OVA. Funders have no direct involvement in the implementation of the project or content of the manuscripts.

\section{Availability of data and materials}

Data included in this study are available upon reasonable request from the corresponding author.

\section{Ethics approval and consent to participate}

The Research Ethics Committee of the Walter Sisulu University approved the research protocol [(Reference: 085/2017]. Permission to implement the study protocol was granted by the Eastern Cape Department of Health and the clinical governance of the hospital. The nature and scope of the study were explained to the participants, whom all gave informed consent before data collection.

\section{Consent for publication}

Participants gave consent for the sharing of the findings of the study. All authors agreed to the publication of this article.

\section{Competing interests}

The authors declare that they have no conflicts of interest.

\section{Author details}

'Department of Public Health, University of Fort Hare, 5 Oxford Street, East London 5201, South Africa. ${ }^{2}$ Population Dynamics and Sexual and Reproductive Health, African Population and Health Research Centre, APHRC Campus, Manga Close, Nairobi, Kenya. ${ }^{3}$ Sociology Department, University of Fort Hare, East London 5201, South Africa. ${ }^{4}$ Department of Family Medicine, East London Hospital Complex, Cecilia Makiwane Hospital, East London, South Africa.

Received: 3 July 2020 Accepted: 8 February 2021

Published online: 16 February 2021

\section{References}

1. Mnyani CN, Tait CL, Armstrong J, Blaauw D, Chersich MF, Buchmann EJ, et al. Infant feeding knowledge, perceptions and practices among women with and without HIV in Johannesburg, South Africa: a survey in healthcare facilities. Int Breastfeed J. 2016;12:17.

2. Ngoma MS, Misir A, Mutale W, Sampalis JS, Elong A, Chisele S, et al. Efficacy of WHO recommendation for continued breastfeeding and maternal CART for prevention of perinatal and postnatal HIV transmission in Zambia. J Int AIDS Soc. 2015;18(1):19352.

3. Avert. 2019. HIV and AIDS in South Africa. Avert, 2019. https://www.avert. org/professionals/hiv-around-world/sub-saharan-africa/south-africa. Accessed 22 Jan 2019

4. Massyn N, Pillay Y, Padarath A, editors. District health barometer 2017/18. Durban: Health Systems Trust; January 2019.

5. South African National Department of Health (SA NDoH). Revised Antiretroviral Treatment Guideline Update for Frontline Clinical Health Professionals. 2013. http://www.sahivsoc.org/Files/FDC\%20Training\%20Ma nual\%2014\%20March\%202013(1).pdf. Accessed 22 Jan 2019.

6. South African National Department of Health (SA NDoH). National Consolidated Guidelines for the prevention of mother-to-child transmission of HIV (PMTCT) and the management of HIV in children, adolescents and adults. 2015. https://sahivsoc.org/Files/ART\%20Guidelines\%2015052015.pdf. Accessed 23 Jan 2019.

7. United Nations Children's Fund (UNICEF) and National Department of Health, KwaZulu-Natal, South Africa (NDoH). Improving breastfeeding in the context of HIV: KZN's breakthrough on breast feeding 2010-2014. https:// www.unicef.org/southafrica/SAF_resources_hivbreastfeeding.pdf. Accessed 23 Jan 2019.

8. World Health Organization (WHO). Guidelines on HIV and infant feeding: Principles and recommendations for infant feeding in the context of HIV and a summary of evidence. Geneva, Switzerland, 2010.

9. Binns $C$, Lee M, Low WY. The long-term public health benefits of breastfeeding. Asia Pac J Public Health. 2016;28(1):7-14.

10. West NS, Schwartz SR, Yende N, Schwartz SJ, Parmley L, Gadarowski MB, et al. Infant feeding by south African mothers living with HIV: implications for future training of health care workers and the need for consistent counseling. Int Breastfeed J. 2019;14:11.

11. Chinkonde JR, Hem MH, Sundby J. HIV and infant feeding in Malawi: public health simplicity in complex social and cultural contexts. BMC Public Health. 2012;12:700.

12. Goga AE, Doherty T, Jackson DJ, Sanders D, Colvin M, Chopra M, et al. Infant feeding practices at routine PMTCT sites, South Africa: results of a prospective observational study amongst HIV exposed and unexposed infants-birth to 9 months. Int Breastfeed J. 2012;7:4. 
13. Waitt C, Low N, Van de Perre P, Lyons F, Loutfy M, Aebi-Popp K. Does $U=U$ for breastfeeding mothers and infants? Breastfeeding by mothers on effective treatment for HIV infection in high-income settings. Lancet HIV. 2018;5(9):e531-6.

14. Chaponda A, Goon TD, Hoque M. Infant feeding practices among HIVpositive mothers at Tembisa hospital, South Africa. Afr J Prim Health Care Fam Med. 2017;9(1):e1-6.

15. Horwood C, Haskins L, Engebretsen IM, Connolly C, Coutsoudis A, Spies L. Improved rates of exclusive breastfeeding at 14 weeks of age in KwaZulu Natal, South Africa: what are the challenges now? BMC Public Health. 2018;18:757.

16. Victora CG, Bahl R, Barros AJD, França GV, Horton S, Krasevec J. Breastfeeding in the 21st century: epidemiology, mechanisms, and lifelong effect. Lancet HIV. 2016;30(387):475-90.

17. Yalcin SS, Berde AS, Yalcin S. Determinants of exclusive breast feeding in sub-Saharan Africa: a multilevel approach. Paediatr Perinat Epidemiol. 2016; 30(5):439-49.

18. WHO/UNICEF. Global strategy for infant and young child feeding. http:// www.who.int/nutrition/topics/infantfeeding/en/. Accessed 8 Feb, 2020.

19. Nieuwoudt S, Manderson L, Norris SA. Infant feeding practices in Soweto, South Africa: implications for healthcare providers. S Afr Med J. 2018;108(9): 756-62.

20. Jama NA, Wilford A, Masango Z, Haskins L, Coutsoudis A, Spies L, et al. Enablers and barriers to success among mothers planning to exclusively breastfeed for six months: a qualitative prospective cohort study in KwaZulu-Natal, South Africa. Int Breastfeed J. 2017;12:43.

21. Statistics South Africa. South Africa Demographic and Health Survey, 2016: Key Indicator Report: SSA Pretoria, 2017.

22. Tuthill E, McGrath J, Young S. Commonalities and differences in infant feeding attitudes and practices in the context of HIV in sub-Saharan Africa: a metasynthesis. AIDS Care. 2014;26(2):214-25.

23. Joint United Nations Programme on HIV/AIDS (UNAIDS). Global Report: UNAIDS Report in the Global AIDs Epidemic. Geneva: UNAIDS; 2019.

24. Joint United Nations Programme on HIV/AIDS (UNAIDS). Global Report: UNAIDS Report in the Global AIDs Epidemic. Geneva: UNAIDS; 2017.

25. Siziba L, Jerling J, Hanekom S, Wentzel-Viljoen E. Low rates of exclusive breastfeeding are still evident in four south African provinces. South African J Clin Nutr. 2015;28(4):170-9.

26. Hazemba AN, Ncama BP, Sithole SL. Promotion of exclusive breastfeeding among HIV-positive mothers: an exploratory qualitative study. Int Breastfeed J. 2016;11:9.

27. Jones DL, Rodriguez VJ, Mandell LN, Lee TK, Weiss SM, Peltzer K. Influences on exclusive breastfeeding among rural HIV-infected south African women: a cluster randomised control trial. AIDS Behav. 2018;22:2966-77.

28. Gejo NG, Weldearegay HG, W/Tinsaie KT, Mekango DE, Woldemichael ES, Buda AS, et al. Exclusive breastfeeding and associated factors among HIV positive mothers in Northern Ethiopia. PloS One. 2019;14(1):e0210782.

29. Tan KL. Factors associated with exclusive breastfeeding among infants under six months of age in peninsular Malaysia. Int Breastfeed J. 2011;6:2.

30. Adeniyi OV, Ajayi Al, Selanto-Chairman N, Goon DT, Boon G, Fuentes YO, et al. Demographic, clinical and behavioural determinants of HIV serostatus non-disclosure to sex partners among HIV-infected pregnant women in the eastern cape, South Africa. PLoS One. 2017;12(8):e0181730.

31. Adeniyi OV, Selanto-Chairman N, Owolabi EO, Ajayi Al, Kayembe DK, Goon DT, et al. Inequality in uptake of isoniazid prevention therapy and Mantoux test among HIV-infected pregnant women in the Eastern Cape, South Africa. BMC Public Health. 2019;19:1407.

32. Greiner T. Exclusive breastfeeding: measurement and indicators. Int Breastfeed J. 2014;9:18.

33. Schwartz SR, Kumwenda N, Kumwenda J, Chen S, Mofenson LM, Taylor AW, et al. Maternal highly active antiretroviral therapy and child HIV-free survival in Malawi, 2004-2009. Matern Child Health J. 2016;20(3):542-9.

34. Madiba S. Factors associated with mixed feeding practices among HIV positive postnatal women in Merafong sub-district, Gauteng Province, South Africa. African Journal for Physical, Health Education, Recreation and Dance. 2015;21(Supplement 2:1):25-38.

35. Ladzani R, Peltzer K, Mlambo MG, Phaweni K. Infant-feeding practices and associated factors of HIV-positive mothers at Gert Sibande, South Africa. Acta Paediatr. 2011;100(4):538-42

36. Ghuman MR, Saloojee H, Morris G. Infant feeding practices in a high HIV prevalence rural district of KwaZulu-Natal, South Africa. South African J Clin Nutr. 2009;22(2):74-9.
37. Goosen C, McLachlan MH, Schübl C. Infant feeding practice during the first 6 months of life in a low-income area of the Western Cape Province. South African J Clin Nutr. 2014;8(2):50-4.

38. Mushaphi LF, Mbhenyane XG, Khoza LB, Amey AKA. Infant-feeding practices of mothers and the nutritional status of infants in the Vhembe District of Limpopo Province. South African J Clin Nutr. 2008;21(2):36-41.

39. Maclntyre UE, Baloyi P. Feeding practices of mothers of four to six week old infants. South African J Clin Nutr. 2000;13(3):127.

40. Budree S, Goddard E, Brittain K, Cader S, Myer L, Zar HJ, et al. Infant feeding practices in a south African birth cohort-a longitudinal study. Matern Child Nutr. 2017;13(3):e12371.

41. Muluye D, Woldeyohannes D, Gizachew M, Tiruneh M. Infant feeding practice and associated factors of HIV positive mothers attending prevention of mother to child transmission and antiretroviral therapy clinics in Gondar town health institutions, Northwest Ethiopia. BMC Public Health. 2012:12:240.

42. Biks GA, Tariku A, Tessema GA. Effects of antenatal care and institutional delivery on exclusive breastfeeding practice in Northwest Ethiopia: a nested case-control study. Int Breastfeed J. 2015;10:30.

43. Hossain M, Islam A, Kamarul T, Hossain G. Exclusive breastfeeding practice during first six months of an infant's life in Bangladesh: a country based cross-sectional study. BMC Pediatr. 2018;18:93.

44. Radhakrishnan S, Balamuruga SS. Prevalence of exclusive breastfeeding practices among rural women in Tamil Nadu. Int J Health Allied Sci. 2012: 1(2):64.

45. Ruan Y, Zhang Q, Li J, Wan R, Bai J, Wang W, et al. Factors associated with exclusive breastfeeding: a cross-sectional survey in Kaiyuan, Yunnan, Southwest China. PLoS One. 2019;14(10):e0223251.

46. El-Gilany A-H, Shady E, Helal R. Exclusive breastfeeding in al-Hassa, Saudi Arabia. Breastfeed Med. 2011;6(4):209-13.

47. Jones JR, Kogan MD, Singh GK, Dee DL, Grummer-Strawn LM. Factors associated with exclusive breastfeeding in the United States. Pediatr. 2011; 128(6):1117-25.

48. Ghwass MMA, Ahmed D. Prevalence and predictors of 6-month exclusive breastfeeding in a rural area in Egypt. Breastfeed Med. 2011;6(4):191-6.

49. Ikeako LC, Ezegwu HU, Nwafor MI, Nwogu-Ikojo E, Okeke T. Infant feeding practice among HIV positive women in Enugu, Nigeria. Br J Med Med Res. 2015;8:61-8

50. Wakwoya EB, Zewudie TA, Gebreslasie KZ. Infant feeding practice and associated factors among HIV positive mothers in Debre Markos referral hospital east Gojam zone, North West Ethiopia. Pan Afr Med J. 2016;24: 300.

51. Sendo EG, Mequanint FT, Sebsibie GT. Infant feeding practice and associated factors among HIV positive mothers attending ART clinic in governmental health institutions of Bahir Dar town, Amhara regional state, Ethiopia. J AIDS Clin Res. 2017;9(1):755.

52. Andare N, Ochol, Chege P. Determinants of infant feeding practices among mothers living with HIV attending prevention of mother to child transmission Clinic at Kiambu Level 4 hospital, Kenya: a cross-sectional study. Nutr J. 2019;18(1):64

53. Tuthill EL, Miller D, Collins SM, Widen EM, Onono M, Young SL, et al. HIV infection, hunger, breastfeeding self-efficacy, and depressive symptoms are associated with exclusive breastfeeding to six months among women in western Kenya: a longitudinal observational study. Int Breastfeed J. 2012;15:4.

54. Sapna S, Ameya A, Rooma S, Aarti P, Rashid A, Narayan K. Prevalence of exclusive breastfeeding and its correlates in an urban slum in western India. Int e-J Sci Med Educ. 2009;3(2):14-8.

55. Rasheed MH, Philemon R, Kinabo GD, Maxym M, Shayo AM, Mmbaga BT. Adherence to exclusive breastfeeding and associated factors in mothers of HIV-exposed infants receiving care at Kilimanjaro chiristian medical Centre, Tanzania. East African Health Res J. 2018;2(1):33-42.

56. Maonga AR, Mahande MJ, Msuya SE. Factors affecting exclusive breastfeeding among women in Muheza District Tanga north eastern Tanzania: a mixed method community based study. Matern Child Health J. 2016;20:77-87.

57. Cai X, Wardlaw T, Brown DW. Global trends in exclusive breastfeeding. Int Breastfeed J. 2012;7:12.

58. Jones G, Steketee RW, Black RE, Bhutta ZA, Morris SS. The Bellagio child survival study group. How many child deaths can we prevent this year? Lancet. 2003;362:65-71.

59. Black RE, Victora CG, Walker SP, Bhutta ZA, Christian P, de Onis M, et al. Maternal and child undernutrition and overweight in low-income and middle-income countries. Lancet. 2013;382(9890):427-51. 
60. Fein SB, Roe B. The effect of work status on initiation and duration of breastfeeding. Am J Public Health. 1998;88(7):1042-6.

61. Abdulwadud OA, Snow ME. Interventions in the workplace to support breastfeeding for women in employment. Cochrane Database Syst Rev. 2012;10(10):CD006177.

62. Setegn T, Belachew T, Gerbaba M, Deribe K, Deribew A, Biadgilign S. Factors associated with exclusive breastfeeding practices among mothers in Goba district, south East Ethiopia: a cross-sectional study. Int Breastfeed J. 2012;7:17.

63. Liben MLGY, Adugnew M, Asrade A, Adamie B, Gebremedin E, Melak Y. Factors associated with exclusive breastfeeding practices among mothers in Dubti town, Afar regional state, Northeast Ethiopia: a community based cross-sectional study. Int Breastfeed J. 2016;11:4.

64. Chekol DA, Biks GA, Gelaw YA, Melsew YA. Exclusive breastfeeding and mothers' employment status in Gondar town, Northwest Ethiopia: a comparative cross-sectional study. Int Breastfeed J. 2017;12:27.

65. Hussein T, Mgongo M, Uriyo JG, Damian DJ, Stray-Pedersen B, Msuya SE, et al. Exclusive breastfeeding rates and factors associated with exclusive breastfeeding practices in northern Tanzania: measurement using two different methodologies-24 hours recall and recall since birth. Int J MCH AIDS. 2019;8(1):32-43.

66. Al-Sahab B, Lanes A, Feldman M, Tamim H. Prevalence and predictors of 6 month exclusive breastfeeding among Canadian women: a national survey. BMC Pediatr. 2010;10:20.

67. Dearden K, Altaye M, Maza I, de Oliva M, Stone-Jimenez M, Morrow AL, et al. Determinants of optimal breastfeeding in peri-urban Guatemala City, Guatemala. Rev Panam Salud Publica. 2002;12(3):185-92.

68. Reimers P. The compelling case for supporting pregnancy and breastfeeding in the workplace: opinion paper. Occup Health Southern Africa. 2017;23(5):14-7.

69. Martin-Wiesner P. A policy review: South Africa's progress in systematising its international and national responsibilities to protect, promote and support breastfeeding. DST-NRF Centre of excellence in human development. URL: https://www.wits.ac.za/coe-human/coe-research-grants/ coe-research-andadvocacyon-breastfeeding/breastfeeding-policy-review/. Accessed 24 Jan 2019.

70. Lande B, Anderson LF, Baerug A, Trygg KU, Lund-Larsen K, Veierod MB, et al. Infant feeding practices and associated factors in the first six months of life: the Norwegian infant nutrition survey. Acta Paediatr. 2003;92(2):152-61.

71. Engebretsen IMS, Wamani H, Karamagi C, Semiyaga N, Tumwine J, Tylleskär T. Low adherence to exclusive breastfeeding in eastern Uganda: a community-based cross-sectional study comparing dietary recall since birth with 24-hour recall. BMC Pediatr. 2007;7:10.

72. Nkala TE, Msuya SE. Prevalence and predictors of exclusive breastfeeding among women in Kigoma region, Western Tanzania: a community based cross-sectional study. Int Breastfeed J. 2011;6:17.

73. Mgongo M, Mosha MV, Uriyo JG, Msuya SE, Stray-Pedersen B. Prevalence and predictors of exclusive breastfeeding among women in Kilimanjaro region, Northern Tanzania: A population based cross-sectional study. Int Breastfeed J. 2013;8:12

74. Alemayehu T, Haidar J, Habte D. Determinants of exclusive breastfeeding practices in Ethiopia. Ethiop J Health Dev. 2009;23(1):12-8.

75. Mihrshahi S, Kabir I, Roy SK, Agho KE, Senarath U, Dibley MJ, et al. Determinants of infant and young child feeding practices in Bangladesh: secondary data analysis of demographic and health survey 2004. Food Nutr Bull. 2010;31:295-313.

76. Giglia RC, Binns CW, Alfonso HS, Scott JA, Oddy WH. The effect of alcohol intake on breastfeeding duration in Australian women. Acta Paediatr. 2008: 97(5):524-9.

77. Ao TT, Sam NE, Massenga EJ, Seage GR, Kapiga SH. Human immunodeficiency virus type 1 among bar and hotel workers in northern Tanzania: the role of alcohol, sexual behaviour, and herpes simplex virus type 2. Sex Transm Dis. 2006;33(3):163-9.

78. Chen JH. Maternal alcohol use during pregnancy, birth weight and early behavioural outcomes. Alcohol. 2012;47(6):649-56.

79. Owolabi EO, Goon DT, Adeniyi VO, Seekoe E. Adult binge drinking: prevalence, frequency and intensity among south Africans. S Afr Fam Pract. 2018;60(2):46-52.

80. Mennella J. Alcohol's effect on lactation. Alcohol Res Health. 2001;25(3):230-4.

81. Giglia R, Binns C. Alcohol and lactation: a systematic review. Nutrition \& Dietetics. 2006;63(2):103-16.

\section{Publisher's Note}

Springer Nature remains neutral with regard to jurisdictional claims in published maps and institutional affiliations.

\section{Ready to submit your research? Choose BMC and benefit from:}

- fast, convenient online submission

- thorough peer review by experienced researchers in your field

- rapid publication on acceptance

- support for research data, including large and complex data types

- gold Open Access which fosters wider collaboration and increased citations

- maximum visibility for your research: over $100 \mathrm{M}$ website views per year

At BMC, research is always in progress.

Learn more biomedcentral.com/submissions 